\title{
Tissue metabolic profiling of lymph node metastasis of colorectal cancer assessed by ${ }^{1} \mathrm{H}$ NMR
}

\author{
HAILONG ZHANG ${ }^{1,2}$, LIANG QIAO ${ }^{3}$, XIAOPENG LI $^{4}$, YANG WAN $^{2,5}$, LI YANG $^{2 *}$ and HUIJUAN WANG ${ }^{* *}$ \\ ${ }^{1}$ Henan Engineering Laboratory of Antibody Medicine, Henan International United Laboratory of Antibody Medicine, \\ Key Laboratory of Cellular and Molecular Immunology, Medical College, Henan University, Kaifeng, Henan 475004; \\ ${ }^{2}$ State Key Laboratory of Biotherapy and Cancer Center, West China School of Pharmacy, West China Hospital, \\ Sichuan University, and Collaborative Innovation Center for Biotherapy, Chengdu, Sichuan 610041; \\ ${ }^{3}$ College of Life Science and Technology, Xinxiang Medical University, Xinxiang, Henan 453003; \\ ${ }^{4}$ Chengdu Jinkai Biotechnology Co., Ltd., Chengdu, Sichuan 610041; ${ }^{5}$ Department of Geriatrics, \\ No.4 West China Teaching Hospital, Sichuan University, Chengdu, Sichuan 610041, P.R. China
}

Received March 28, 2016; Accepted April 25, 2016

DOI: 10.3892/or.2016.5175

\begin{abstract}
Lymph node metastasis is a decisive prognostic and therapeutic staging factor for colorectal cancer (CRC), which is one of the most prevalent types of cancer and a malignant tumor. The metabolic profiling of tissue samples from a large cohort of lymph node non-metastatic CRC patients $(n=73)$, lymph node metastatic CRC patients $(n=52)$ and normal controls $(n=41)$ was performed using ${ }^{1} \mathrm{H}$ nuclear magnetic resonance (NMR) together with multivariate statistical analyses. Excellent separation was obtained between CRC patients and normal controls, and CRC patients were also perfectly classified according to lymph node metastasis.
\end{abstract}

Correspondence to: Dr Huijuan Wang, Henan Engineering Laboratory of Antibody Medicine, Henan International United Laboratory of Antibody Medicine, Key Laboratory of Cellular and Molecular Immunology, Medical College, Henan University, Jinming Road, Kaifeng, Henan 475004, P.R. China

E-mail: juanjuan5891@163.com

Dr Li Yang, State Key Laboratory of Biotherapy and Cancer Center, West China School of Pharmacy, West China Hospital, Sichuan University, and Collaborative Innovation Center for Biotherapy, No. 17, Section 3, Renmin South Road, Chengdu, Sichuan 610041, P.R. China

E-mail: yl.tracy73@gmail.com

${ }^{*}$ Contributed equally

Abbreviations: NMR, nuclear magnetic resonance; PCA, principal component analysis; PLS-DA, partial least squares-discriminant analysis; OPLS-DA, orthogonal partial least squares-discriminant analysis; VIP, variable importance in the projection; ROC, receiver operating characteristic; AUC, area under the curve

Key words: colorectal cancer, lymph node metastasis, tissue, metabolic profiling, nuclear magnetic resonance
Forty-two distinguishing metabolites were identified, which revealed disturbance of glycolysis, glutaminolysis, fatty acid metabolism, choline metabolism and amino acids, suggesting that cellular functions in energy production, macromolecular synthesis, oxidative stress and immune escape of cancer cells are affected in CRC. In total, 10 tissue metabolites were significantly disturbed between non-metastatic and metastatic CRC patients. The present study firstly staged CRC patients by lymph node metastasis by metabolomic approach. The identified metabolites may be associated with the neoplasia, invasion and metastasis of the tumor. The results suggest the promising application of these metabolites in clinical therapy, and further understanding of the related mechanism warrants further investigation.

\section{Introduction}

Colorectal cancer (CRC) is one of the most prevalent types of cancer worldwide (1). According to the American Cancer Society, CRC is the third most common malignancy among both genders in the USA (2), and more than 136,000 new CRC cases were diagnosed in 2014 and an estimated 50,000 deaths were reported in 2015 in the USA alone (3). In fact, current estimates predict that $5 \%$ of the population will be diagnosed with CRC at some point in their lifetime (4). Most CRC patients are diagnosed at an advanced stage with lymph node metastasis. Although the disease has good therapeutic response at early stages, advanced stages are associated with poor prognosis. Among various metastatic pathways, the lymph node system plays an important role in affecting the prognosis of CRC patients, and serves as the most frequent pathway for metastasis. In theory, CRC patients with localized tumor and without lymph node or distant metastases (i.e., stages I and II), may be cured by surgical resection alone. Unfortunately, only $40 \%$ of CRC patients are diagnosed at early, localized stages of the disease. The overall five-year survival rate (FYSR) can reach $80-90 \%$ for non-metastatic CRC patients, while those diagnosed at advanced stages have only a 13\% FYSR (5). 
Unfortunately, mechanisms underlying metastasis are still largely unknown. Thus, identifying novel potential biomarkers for CRC and investigating the molecular mechanisms of CRC metastasis are essential for diagnosis, treatment and prognosis of this disease.

Cancer cells exhibit distinct metabolic phenotypes, which are essential for supporting high proliferative rates. Abnormal metabolism is an important characteristic of cancer, such as the identified Warburg effect (6). The key metabolic pathways along with distinguishing metabolites have been the focus of many cancer studies (7-9). Metabolomics (10), as the end-point of the '-omics' cascade and therefore the last step before phenotype, has been a recently developed technology for the detection, identification and quantification of small molecular weight metabolites, which are included in the metabolism of a cellular or biological system at a specified time under specific environmental conditions $(11,12)$, resulting in rapid progress in identifying biomarkers for the early prediction and diagnosis of cancers $(13,14)$ as well as in obtaining fundamental mechanistic insights into carcinogenesis, staging and metastasis of cancer over the past decade (15-17). Recent technological advances in mass spectrometry (MS) and nuclear magnetic resonance (NMR) spectroscopy have also further improved the spectral resolution and sensitivity for cancer metabolomic study (18). Recently, metabolomics have been applied in human CRC study (16,19-21). These studies have mainly focused on biomarker discovery for CRC or discrimination of CRC rather than being based on lymph node metastasis, an important prognostic factor in CRC. There has been a lack of comprehensive studies on discriminating lymph node metastatic CRC tissues from lymph node non-metastatic CRC tissues.

In this study, we utilized an NMR-based non-targeted metabolomic approach in conjunction with multivariate statistical analyses to investigate differential metabolites of tissue samples between normal controls and CRC patients, especially focusing on those disturbances present in patients with lymph node metastasis. To our knowledge, this was the first instance where an unbiased high-throughput approach was adopted to identify progressive metabolites altered in the lymph node metastasis of CRC. We aimed to identify potential metabolic biomarkers of metastasis for early diagnosis, staging and therapeutic strategies. The role and the underlying mechanisms of $\mathrm{CRC}$ warrant further investigation.

\section{Materials and methods}

Chemicals. High-performance liquid chromatography (HPLC) grade chloroform and methanol were purchased from Thermo Fisher Scientific. Trimethylsilylpropionic acid-d4 sodium salt (TSP) was purchased from Sigma-Aldrich. Deuterium water $(99.8 \%$ D) was purchased from Cambridge Isotope Laboratories (CIL). All of the other chemicals used in this study were purchased from Sigma-Aldrich and were analytically pure and of culture grade.

Sample collection. The study protocol was approved by the Ethics Committee of the West China Hospital of Sichuan University. The CRC patients included in the study provided written informed consent in accordance with the institutional guidelines before sample collection. In order to avoid interference, all subjects enrolled in this study did not receive any chemotherapy or radiation therapy prior to surgical treatment. During 2009-2010, 125 CRC patients were recruited, and a total of 166 surgical specimens were collected. Among them, 41 normal control tissues were extracted at least $5-10 \mathrm{~cm}$ away from the edge of a tumor from the same sample, thus 82 cases included matched tumor and normal control tissues. The pathological diagnosis of CRC was confirmed using routine histopathological H\&E stained specimens. The clinical characteristics of the patients are provided in Table I. Tissue samples were diagnosed for TNM stage: no lymph node metastasis ( $n=73$; males, 36; females, 37$)$, lymph node metastasis ( $n=52$; males, 29; females, 23). The dissected tissues were immediately frozen in liquid nitrogen to stop any enzymatic or chemical reactions in the operating room and stored at $-80^{\circ} \mathrm{C}$.

Sample preparation and ${ }^{1} H$ NMR spectroscopic analysis. To extract the significant metabolites (e.g., carbohydrates, lipids, amino acids and other small metabolites), the typical frozen sample size was $100 \mathrm{mg}$. Methanol, chloroform and distilled water was ice-cold before the extraction. Approximately $100 \mathrm{mg}$ of each frozen tissue sample was placed into $1.5-\mathrm{ml}$ microcentrifuge vials and weighed. The weighed tissues were minced using liquid nitrogen. A total of $400 \mu 1$ methanol ( $4 \mathrm{ml} / \mathrm{g}$ of tissue) and $85 \mu \mathrm{l}$ distilled water $(0.85 \mathrm{ml} / \mathrm{g}$ of tissue) were added and the mixture was vortexed for $1 \mathrm{~min}$. A total of $200 \mu \mathrm{l}$ chloroform $(2 \mathrm{ml} / \mathrm{g}$ of tissue) was then added. After vortexing, the samples were kept on ice for $30 \mathrm{~min}$ to extract the metabolites, followed by centrifugation at 1,000 $\mathrm{x} g$ for $30 \mathrm{~min}$ at $4^{\circ} \mathrm{C}$. This procedure separated the suspension into three phases, including the top water phase, the middle denatured protein phase, and the bottom lipid phase. The upper aqueous phase of each sample was transferred into a new Eppendorf vial and evaporated to dryness. The residue was reconstituted with $580 \mu \mathrm{l}$ of $\mathrm{D}_{2} \mathrm{O}$ containing $30 \mu \mathrm{M}$ PBS (pH, 7.4) and 0.1-0.5 mM TSP, which respectively provided the deuterium lock signal for the NMR spectrometer and the chemical shift reference $(\delta 0.0)$. The solution was centrifuged at $12,000 \mathrm{x} \mathrm{g}$ for $5 \mathrm{~min}$ at $4^{\circ} \mathrm{C}$, and $550 \mu \mathrm{l}$ was transferred into a 5-mm NMR tube for NMR spectroscopy (22).

The ${ }^{1} \mathrm{H}$ NMR experiments were carried out on a Bruker Avance II 600 spectrometer (Bruker BioSpin, Rheinstetten, Germany) operating at $600.13 \mathrm{MHz}$ and a temperature of $300 \mathrm{~K}$. A one-dimensional spectrum for each sample was acquired by using a standard (1D) Carr-Purcell-MeiboomGill (CPMG) pulse sequence to observe metabolite signals. The water signal was suppressed with a relaxation delay of $5 \mathrm{sec}$. Spectra results were the summation of 67 free induction decays (FIDs), which were collected into $64 \mathrm{~K}$ data points with a spectral width of $12,335.5 \mathrm{~Hz}$ and an acquisition time of $2.66 \mathrm{sec}$. The total pulse recycle delay was $7.66 \mathrm{sec}$. Prior to Fourier transformation, the FIDs were weighted by a Gaussian function with line-broadening factor of $0.3 \mathrm{~Hz}$ and spectra were referenced to TSP resonance at $\delta 0.0$ (23).

Data processing and multivariate statistical analysis. The data processing was carried out using MestReNova-6.1.1-6384 software. The raw NMR data (FIDs) were manually Fourier transformed using it. The ${ }^{1} \mathrm{H}$ NMR spectra of all tissue samples were phase-adjusted and baseline-corrected after 
Table I. Clinical characteristics of the CRC patients and normal controls analyzed by ${ }^{1} \mathrm{H}$ NMR.

\begin{tabular}{|c|c|c|c|}
\hline & \multicolumn{2}{|c|}{ CRC patients } & \multirow[b]{2}{*}{$\begin{array}{l}\text { Normal } \\
\text { controls }\end{array}$} \\
\hline & $\begin{array}{l}\text { Lymph node } \\
\text { non-metastatic }\end{array}$ & $\begin{array}{c}\text { Lymph node } \\
\text { metastatic }\end{array}$ & \\
\hline No. of subjects & 73 & 52 & 41 \\
\hline \multicolumn{4}{|l|}{ Age in years } \\
\hline Mean & 57.8 & 51 & 56.8 \\
\hline Range & $(28-86)$ & $(31-71)$ & $(35-85)$ \\
\hline Gender (male/female) & $36 / 37$ & $29 / 23$ & $16 / 25$ \\
\hline \multicolumn{4}{|l|}{ Nutritional status } \\
\hline SGA-A & 60 & 43 & 41 \\
\hline SGA-B & 11 & 6 & \\
\hline SGA-C & 2 & 3 & \\
\hline \multicolumn{4}{|l|}{ Histology } \\
\hline Adenocarcinoma & 73 & 52 & \\
\hline \multicolumn{4}{|l|}{ Pathological grade } \\
\hline PD & 17 & 18 & \\
\hline MD & 48 & 30 & \\
\hline WD & 5 & 3 & \\
\hline NA & 3 & 1 & \\
\hline \multicolumn{4}{|l|}{ TNM stage } \\
\hline I & 34 & & \\
\hline IIA & 38 & & \\
\hline IIC & 1 & & \\
\hline IIIA & & 6 & \\
\hline IIIB & & 28 & \\
\hline IIIC & & 4 & \\
\hline IVA & & 14 & \\
\hline
\end{tabular}

CRC, colorectal cancer; NMR, nuclear magnetic resonance; SGA-A, well nourished; SGA-B, mildly-moderately malnourished; SGA-C, severely malnourished; $\mathrm{PD}$, poorly differentiated; $\mathrm{MD}$, moderately differentiated; WD, well differentiated; NA, not applicable.

referencing to TSP resonance at $\delta 0.0$. The one-dimensional spectra ranging from 0.5 to $9.5 \mathrm{ppm}$ was divided into 4,500 integral segments $80.002 \mathrm{ppm}$ in width. The regions of 4.66-4.94 and 3.34-3.37 ppm were both removed for excluding the effect of imperfect water and methanol signals. Moreover, to eliminate the dilution or bulk mass differences among samples due to the different weight of tissue, the integrated data were normalized before pattern recognition analysis and assigned the same total integration value for each spectrum.

The normalized data were exported into statistical software SIMCA-P+ 11 (Umetrics AB), with which principal component analysis (PCA), partial least squares-discriminant analysis (PLS-DA), and orthogonal partial least squares-discriminant analysis (OPLS-DA) were performed using standard procedures. The analyses were conducted with reference to the established methods $(24,25)$. The PLS-DA models were cross-validated by a 200 -times permutation analysis, and the resulting $\mathrm{R}^{2}$ and $\mathrm{Q}^{2}$ values were calculated,

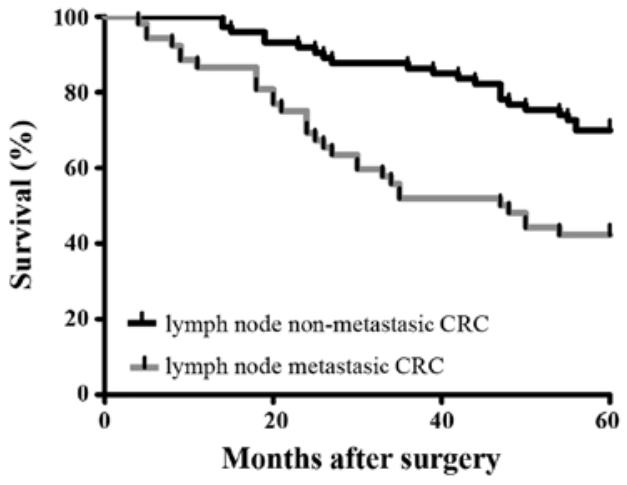

Figure 1. The FYSR of patients enrolled in this study. FYSR, five-year survival rate.

which were used to assess the amount of variation. In order to enhance interpretability of the model, the model coefficients were then back-calculated from the y variables incorporating the weight of the variables, which as specific model coefficients locate the NMR variables. The coefficient plots were generated with Matlab scripts, which were color-coded with the absolute value of coefficients (r).

To identify the significant metabolites between tumor tissues and normal controls, the variable importance in the projection (VIP) $>1$ values of all peaks from OPLS-DA models and unpaired $(\mathrm{p}<0.05)$ to the chemical shifts were analyzed and taken as coefficients. Only those metabolites meeting VIP $>1$ and $\mathrm{p}<0.05$, were identified as distinguishing ones. The metabolite identification met two conditions: the corresponding chemical shift and multiplicity, according to previous literature and the Human Metabolome Database (http://www.hmdb.ca/).

\section{Results}

Study population. In this study, a total of 166 tissue samples were investigated, 125 of which were CRC tissue samples. The CRC tissues were classified into two subgroups, a lymph node non-metastatic CRC group (males, 36; females, 37; age range, 28-86 years; median age, 57.8 years) and a lymph node metastatic CRC group (males, 29; females, 23; age range, 31-71 years; median age, 51 years). Forty-one tissue samples were normal controls (males, 16; females, 25; age range, 35-85 years; median age, 56.8 years). The clinicopathological characteristics of the CRC patients are summarized in Table I. The nutritional status, tissue histology, pathological grade and TNM stages are presented in Table I. The Stages of the lymph node non-metastatic CRC patients were determined according to the American Joint Committee on Cancer (AJCC) for CRC: stage I, 34 patients; stage IIA, 38 patients; stage IIC, 1 patient. The stages of the lymph node metastatic CRC patients were as follows: stage IIIA, 6 patients; stage IIIB, 28 patients; stage IIIC, 4 patients; stage IVA, 14 patients. The survival rate of the patients enrolled in this study is also shown (Fig. 1). The FYSR of the lymph node non-metastatic CRC patients was significantly higher than that of the lymph node metastatic CRC patients.

${ }^{l} H$ NMR metabolic profiling of CRC tissue samples. The representative ${ }^{1} \mathrm{H}$ NMR spectrum of aqueous phase extracts 


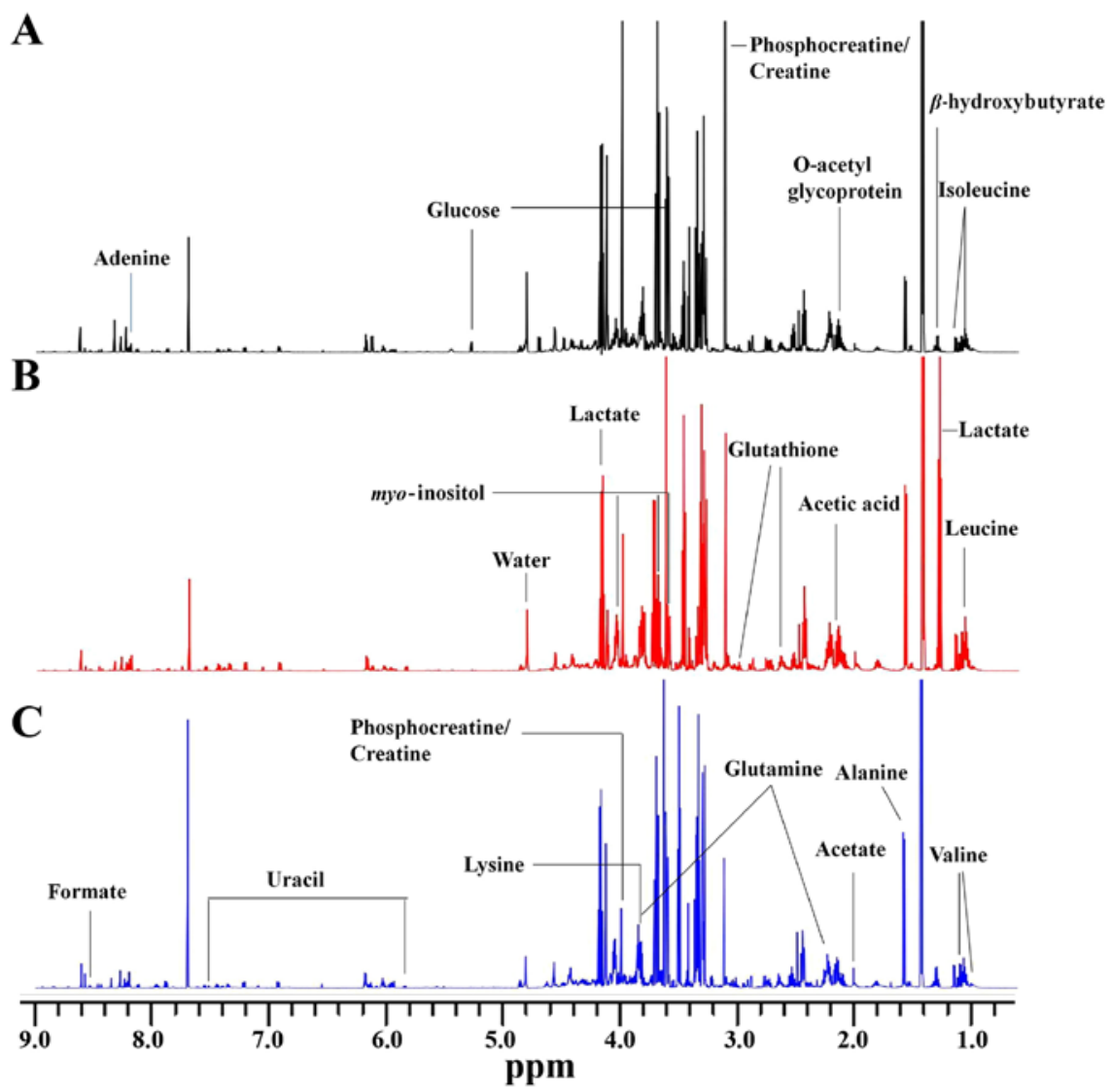

Figure 2. Representative $600 \mathrm{MHz}{ }^{1} \mathrm{H}$ NMR spectra ( $\left.\delta 9.5-\delta 0.5\right)$ of the tissue samples. (A) Normal control sample, (B) non-metastatic CRC sample, (C) metastatic CRC sample. NMR, nuclear magnetic resonance; CRC, colorectal cancer.

of non-metastatic CRC, metastatic CRC and normal control tissues are shown (Fig. 2A-C), respectively. The spectrum was processed and converted into 4,500 integral regions of $\delta 0.002 \mathrm{ppm}$ width as described in 'Materials and methods'. The major spectrum can be assigned to specific metabolites by comparing their chemical shifts and spectral peak multiplicities with literature data and spectra of standards acquired in Human Metabolome Database (http://www.hmdb.ca/). Fig. 2 shows clear visible differences among the three groups. As a result, a series of altered endogenous metabolites were observed. The spectral region from 0.5 to $5.0 \mathrm{ppm}$ included many signals, such as leucine, valine, $\beta$-hydroxybutyrate, lactate, acetate, glutamine, glutathione (GSH), acetic acid, myo-inositol, lysine and glucose. The specific signals from 5.0 to $9.5 \mathrm{ppm}$ were few, including glucose, uracil, adenine, formate and several unknown signals. These major metabolites are involved in multiple metabolic processes, especially in energy metabolism $(25,26)$.

Multivariate statistical analysis of non-metastatic tissues, metastatic tissues and normal controls. First, PCA, as an unsupervised multivariate statistical model, was applied to illustrate intrinsic variations among non-metastatic CRC, metastatic CRC and normal control tissues after ${ }^{1} \mathrm{H}$ NMR data normalization. The PCA score plot $\left(2 \mathrm{PCs}, \mathrm{R}^{2} \mathrm{X}=0.44\right.$, $\mathrm{Q}^{2}=0.277$ ) showed that $\mathrm{CRC}$ samples (color triangles) and normal controls (black blocks) were scattered into different regions (Fig. 3A). The majority of samples were located in the
95\% confidence interval. Therefore, to ensure the maximum information, all of the samples were used in the following analysis. However, there was no significant difference between the non-metastatic (red triangles) and metastatic (blue triangles) CRC samples in the PCA score plot (Fig. 3A). Next, to enhance the separation of the three groups, OPLS-DA was performed. As shown in Fig. 3B, OPLS-DA showed a dramatic difference between the CRC and normal control samples as well as an obvious trend of profile separation between the non-metastatic and metastatic CRC samples. Moreover, model validation assured that the explained variation $\left(\mathrm{R}^{2}=0.87\right)$ and the predictive capability $\left(Q^{2}=0.85\right)$ were significantly high, which demonstrated that it was an excellent model and reliable for explaining and predicting the variations (Fig. 3C). The OPLS-DA loadings were colored according to the absolute value of the coefficients (Fig. 3D) and showed the significant class-discriminating metabolites responsible for the clustering patterns. The signals in the positive quadrant represented the upregulated metabolites in CRC tissues compared to normal controls. On the other hand, the negative signals corresponded to the downregulated metabolites in the CRC tissues.

To prove the robustness of the OPLS-DA model in discriminating CRC from controls, receiver operating characteristic (ROC) analysis was carried out. Area under the curve (AUC) value was 0.748 (Fig. 4). This diagnostic model was used just to identify the tissue metabolic biomarkers rather than to replace the established histopathologic diagnostic standard for CRC. Using a combination of the VIP $>1$ with $\mathrm{p}<0.05$, 
A

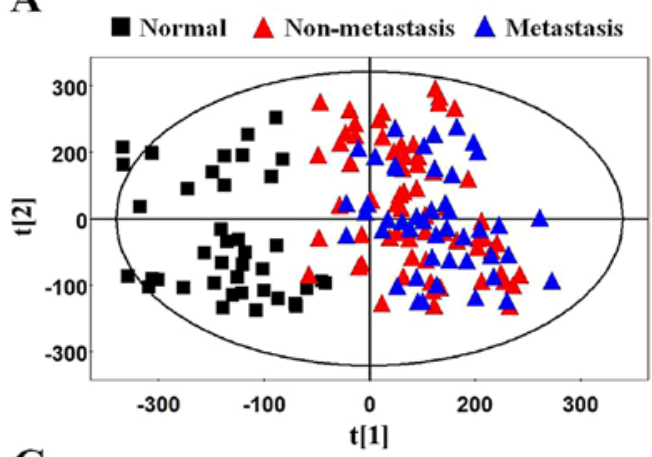

C

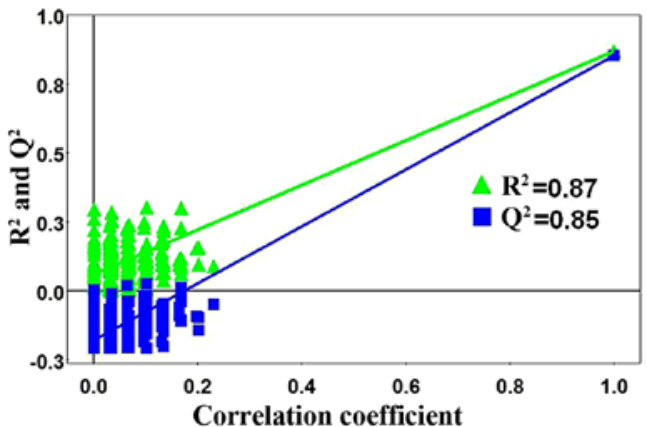

B

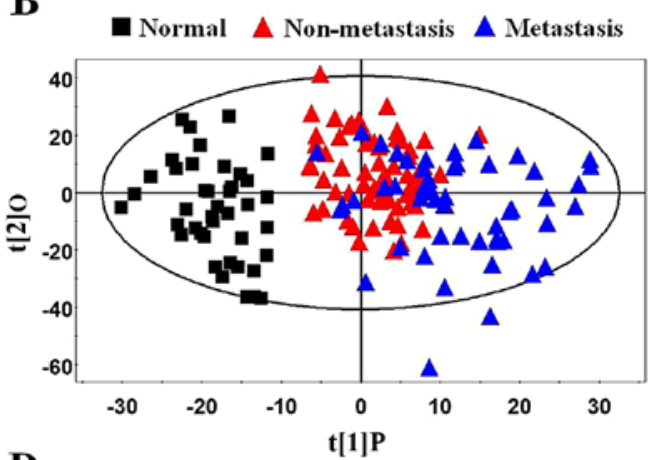

D

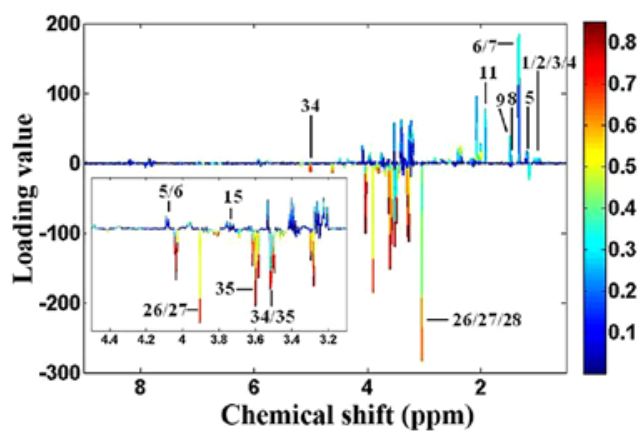

Figure 3. Metabolic profiling between CRC tissues and normal controls. (A) PCA score plot between the CRC tissues and normal controls. Black blocks, normal controls $(n=41)$; red triangles, non-metastatic CRC patients $(n=73)$; blue triangles, metastatic CRC patients $(n=52)$. (B) OPLS-DA score plot based on the same samples. (C) Statistical validation of the corresponding PLS-DA model using permutation analysis (200 times). $\mathrm{R}^{2}$ is the explained variance, and $\mathrm{Q}^{2}$ is the predictive ability of the model. (D) The colormap shows the significance of the metabolite variations between the two classes. Peaks in the positive direction indicate the increased metabolites in CRC tissues in comparison to normal controls. Deceased metabolites in CRC tissues are presented as peaks in the negative direction. CRC, colorectal cancer; PCA, principal component analysis; OPLS-DA, orthogonal partial least squares-discriminant analysis; PLS-DA, partial least squares-discriminant analysis.

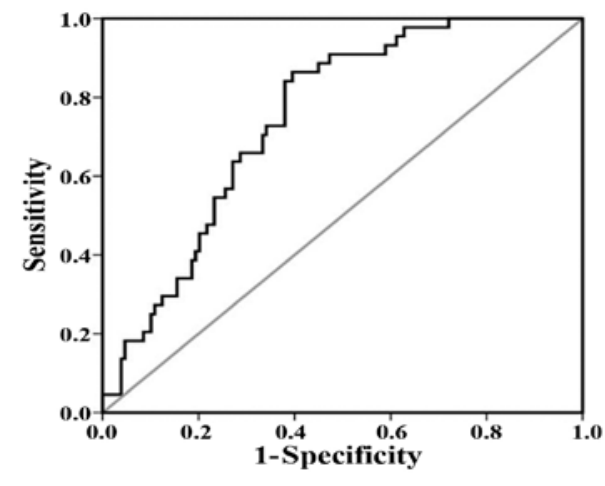

Figure 4. ROC analysis between the non-metastatic and metastatic CRC samples. ROC analysis was performed using the Y-predicted value determined by PLS-DA model. ROC, receiver operating characteristic; CRC, colorectal cancer; PLS-DA, partial least squares-discriminant analysis.

the 30 and 39 distinguishing metabolites were identified for the non-metastatic and metastatic CRC cases (Table II). Among them, 28 differential metabolites were identified both in the non-metastatic and metastatic CRC cases. The changed metabolites in the CRC cases included upregulated and downregulated levels. The increased tissue metabolites were lactate, threonine, lipid, succinate, dimethylglycine (DMG), serine, arginine and uracil, whereas the decreased metabolites included glucose, ketoglutarate, phosphocreatine, creatine and myo-inositol. The abnormal changes in tissue metabolites reflected the metabolic phenotype. Moreover, they also provide insight into the underlying metabolism of CRC, improving the systematic understanding of the pathological changes of this disease.

Performing metabolic profiling between non-metastatic and metastatic CRC samples will be valuable in identifying potential biomarkers of lymph node metastatic CRC and understanding the molecular mechanisms involved. To our knowledge, this study was the first to show the differences in metabolic profiling between non-metastatic and metastatic CRC cases. The score plot of OPLS-DA (2PCs, $R^{2} Y=0.742$, $\left.\mathrm{Q}^{2}=0.349\right)$ showed that the metastatic $\mathrm{CRC}$ cases could be separated from non-metastatic CRC cases (Fig. 5A). To get an insight into the type of metabolites responsible for the clustering patterns between the subjects, the loading plots corresponding to OPLS-DA models are presented (Fig. 5B). The relative changes in metabolites with significant correlation coefficients were a major discriminating factor between non-metastatic and metastatic CRC cases, implying the biochemical alterations in different morbidity. The permutation analysis of the corresponding OPLS-DA is shown in Fig. 5C, which indicated that the current model was reliable for explaining and predicting the observed variations. Also, to further confirm the performance of the model, each class of non-metastatic or metastatic CRC samples was randomly classified into a training set (80\% samples) and a testing set (20\% samples). Prediction parameters of the testing sample using the OPLS-DA model established with the training set were as follows: $R^{2} X=0.196, R^{2} Y=0.754, Q^{2}=0.245$. As shown 
Table II. Differential tissue metabolites identified among the non-metastatic CRC, metastatic CRC and normal control samples.

\begin{tabular}{|c|c|c|c|c|c|c|c|c|}
\hline \multirow[b]{2}{*}{ Metabolites } & \multirow{2}{*}{$\begin{array}{l}\text { Chemical } \\
\text { shift }\end{array}$} & \multirow[b]{2}{*}{ Mutiplicity $^{\mathrm{a}}$} & \multicolumn{3}{|c|}{$\begin{array}{l}\text { Non-metastatic vs. } \\
\text { normal controls }\end{array}$} & \multicolumn{3}{|c|}{$\begin{array}{l}\text { Metastatic vs. } \\
\text { normal controls }\end{array}$} \\
\hline & & & $\mathrm{VIP}^{\mathrm{b}}$ & P-value & $\mathrm{FC}^{\mathrm{d}}$ & $\mathrm{VIP}^{\mathrm{b}}$ & P-value ${ }^{c}$ & $\mathrm{FC}^{\mathrm{d}}$ \\
\hline \multirow[t]{2}{*}{ 2-Hydroxyisovaleric acid } & 0.98 & $\mathrm{~d}$ & 1.91 & $<0.001$ & 1.28 & 1.41 & $<0.001$ & 1.32 \\
\hline & 4.13 & $\mathrm{~d}$ & 1.63 & $<0.001$ & 1.14 & 1.67 & $<0.05$ & 1.11 \\
\hline \multirow[t]{2}{*}{ Isoleucine } & 0.95 & $\mathrm{t}$ & 1.99 & 0.112 & 1.07 & 1.58 & 0.410 & 1.04 \\
\hline & 1.01 & $\mathrm{~d}$ & 0.89 & $<0.05$ & 1.10 & 1.00 & $<0.05$ & 1.11 \\
\hline Leucine & 0.96 & $\mathrm{t}$ & 0.80 & $<0.05$ & 1.11 & 1.32 & $<0.05$ & 1.13 \\
\hline \multirow[t]{2}{*}{ Valine } & 0.99 & $\mathrm{~d}$ & 1.91 & $<0.001$ & 1.28 & 1.41 & $<0.001$ & 1.32 \\
\hline & 1.05 & $\mathrm{~d}$ & 1.26 & $<0.001$ & 1.30 & 1.33 & $<0.001$ & 1.36 \\
\hline \multirow[t]{2}{*}{$\beta$-hydroxybutyrate } & 1.2 & $\mathrm{~d}$ & 1.61 & 0.192 & 1.17 & 1.71 & $<0.05$ & 1.36 \\
\hline & 4.16 & $\mathrm{~m}$ & 0.48 & $<0.05$ & 1.14 & 0.44 & 0.737 & 1.01 \\
\hline \multirow[t]{2}{*}{ Lactate } & 1.33 & $\mathrm{~d}$ & 1.08 & $<0.001$ & 1.22 & 2.12 & $<0.001$ & 1.21 \\
\hline & 4.11 & $\mathrm{q}$ & 0.86 & $<0.001$ & 1.18 & 1.51 & $<0.001$ & 1.14 \\
\hline Threonine & 1.33 & $\mathrm{~d}$ & 1.08 & $<0.001$ & 1.22 & 2.12 & $<0.001$ & 1.21 \\
\hline Alanine & 1.48 & $\mathrm{~d}$ & 1.87 & $<0.001$ & 1.46 & 1.27 & $<0.001$ & 1.39 \\
\hline VLDL: $-\mathrm{CH}_{2}-\mathrm{CH}_{2}-\mathrm{CH}_{2} \mathrm{O}$ & 1.58 & br & 1.36 & $<0.001$ & -1.32 & 0.86 & $<0.05$ & -1.16 \\
\hline Thymine & 1.86 & $\mathrm{~d}$ & 1.20 & $<0.001$ & -1.42 & 0.90 & 0.172 & -1.15 \\
\hline Acetate & 1.93 & $\mathrm{~s}$ & 0.08 & 0.335 & -1.09 & 1.75 & $<0.001$ & 3.64 \\
\hline Lipid, $-\mathrm{CH}_{2}-\mathrm{CH}=\mathrm{CH}$ & 2.03 & br & 1.85 & $<0.05$ & 1.11 & 2.04 & $<0.001$ & 1.20 \\
\hline O-acetyl glycoprotein & 2.07 & $\mathrm{~s}$ & 1.14 & $<0.001$ & 1.20 & 1.56 & $<0.001$ & 4.92 \\
\hline Acetic acid & 2.08 & $\mathrm{~s}$ & 1.14 & $<0.001$ & 1.20 & 1.56 & $<0.001$ & 4.92 \\
\hline \multirow[t]{2}{*}{ Glutamine } & 2.14 & $\mathrm{~m}$ & 0.98 & 0.721 & 1.01 & 1.53 & 0.088 & 1.06 \\
\hline & 3.77 & $\mathrm{~m}$ & 0.73 & $<0.001$ & 1.11 & 1.09 & $<0.001$ & 1.08 \\
\hline Lipid, $-\mathrm{CH}_{2}-\mathrm{C}=\mathrm{O}$ & 2.26 & br & 0.28 & 0.802 & 1.01 & 1.15 & $<0.05$ & 1.10 \\
\hline Acetoacetate & 2.28 & $\mathrm{~s}$ & 0.43 & 0.065 & 1.09 & 1.11 & $<0.05$ & 1.17 \\
\hline Succinate & 2.41 & $\mathrm{~s}$ & 1.23 & $<0.05$ & 1.18 & 1.88 & $<0.001$ & 1.41 \\
\hline \multirow[t]{2}{*}{$\alpha$-ketoglutarate } & 2.45 & $\mathrm{t}$ & 1.17 & $<0.001$ & -1.24 & 0.84 & $<0.05$ & -1.19 \\
\hline & 3.01 & $\mathrm{t}$ & 0.47 & 0.191 & -1.06 & 1.06 & 0.906 & -1.01 \\
\hline \multirow[t]{2}{*}{ Glutathione } & 2.56 & $\mathrm{~m}$ & 2.28 & $<0.001$ & 1.36 & 2.46 & $<0.001$ & 1.35 \\
\hline & 2.96 & $\mathrm{~m}$ & 0.81 & $<0.001$ & 1.22 & 1.76 & $<0.001$ & 1.24 \\
\hline Methylamine & 2.59 & $\mathrm{~s}$ & 0.73 & $<0.001$ & 1.26 & 1.33 & $<0.05$ & 1.20 \\
\hline Dimethylamine & 2.73 & $\mathrm{~s}$ & 0.24 & 0.453 & -1.03 & 1.74 & $<0.05$ & 1.18 \\
\hline Sarcosine & 2.75 & $\mathrm{~s}$ & 0.12 & 0.906 & 1.01 & 1.04 & $<0.05$ & 1.18 \\
\hline TMA & 2.88 & $\mathrm{~s}$ & 0.92 & 0.470 & 1.08 & 1.58 & $<0.05$ & 1.31 \\
\hline \multirow{2}{*}{ DMG } & 2.91 & $\mathrm{~s}$ & 1.38 & 0.252 & 1.12 & 1.42 & $<0.05$ & 1.33 \\
\hline & 3.71 & $\mathrm{~s}$ & 2.55 & $<0.001$ & 1.46 & 2.44 & $<0.001$ & 1.68 \\
\hline \multirow[t]{2}{*}{ Phosphocreatine } & 3.04 & $\mathrm{~s}$ & 2.89 & $<0.001$ & -2.11 & 3.22 & $<0.001$ & -1.94 \\
\hline & 3.93 & $\mathrm{~s}$ & 1.54 & $<0.001$ & -1.93 & 2.34 & $<0.001$ & -1.83 \\
\hline \multirow[t]{2}{*}{ Creatine } & 3.04 & $\mathrm{~s}$ & 2.89 & $<0.001$ & -2.11 & 3.22 & $<0.001$ & -1.94 \\
\hline & 3.94 & $\mathrm{~s}$ & 1.54 & $<0.001$ & -1.93 & 2.34 & $<0.001$ & -1.83 \\
\hline Creatinine & 3.04 & $\mathrm{~s}$ & 2.89 & $<0.001$ & -2.11 & 3.22 & $<0.001$ & -1.94 \\
\hline $\mathrm{PC}$ & 3.21 & $\mathrm{~s}$ & 1.37 & $<0.05$ & 1.16 & 1.20 & $<0.05$ & 1.16 \\
\hline GPC & 3.23 & $\mathrm{~s}$ & 1.75 & $<0.001$ & 1.29 & 1.58 & $<0.05$ & 1.19 \\
\hline Arginine & 3.25 & $\mathrm{t}$ & 1.24 & $<0.001$ & 1.73 & 1.37 & $<0.001$ & 1.40 \\
\hline Trimethylamine- $N$-oxide & 3.27 & $\mathrm{~s}$ & 1.24 & $<0.001$ & 1.87 & 1.37 & $<0.001$ & 1.51 \\
\hline \multirow[t]{2}{*}{ Taurine } & 3.27 & $\mathrm{t}$ & 3.36 & $<0.05$ & 1.09 & 3.81 & $<0.05$ & 1.09 \\
\hline & 3.43 & $\mathrm{t}$ & 1.14 & $<0.001$ & 2.22 & 1.61 & $<0.001$ & 1.71 \\
\hline \multirow[t]{2}{*}{ Glucose } & 3.55 & $\mathrm{dd}$ & 3.29 & $<0.001$ & -2.08 & 3.77 & $<0.001$ & -2.02 \\
\hline & 5.23 & dd & 3.03 & $<0.001$ & -5.16 & 3.11 & $<0.001$ & -4.41 \\
\hline \multirow[t]{3}{*}{ myo-inositol } & 3.55 & $\mathrm{dd}$ & 3.29 & $<0.001$ & -2.08 & 3.77 & $<0.001$ & -2.02 \\
\hline & 3.63 & $\mathrm{t}$ & 2.81 & $<0.001$ & -1.93 & 3.45 & $<0.001$ & -1.99 \\
\hline & 4.06 & $\mathrm{t}$ & 3.37 & $<0.001$ & -1.87 & 3.85 & $<0.001$ & -1.95 \\
\hline
\end{tabular}


Table II. Continued.

\begin{tabular}{|c|c|c|c|c|c|c|c|c|}
\hline \multirow[b]{2}{*}{ Metabolites } & \multirow{2}{*}{$\begin{array}{c}\text { Chemical } \\
\text { shift }\end{array}$} & \multirow[b]{2}{*}{ Mutiplicity $^{\mathrm{a}}$} & \multicolumn{3}{|c|}{$\begin{array}{l}\text { Non-metastatic vs. } \\
\text { normal controls }\end{array}$} & \multicolumn{3}{|c|}{$\begin{array}{l}\text { Metastatic vs. } \\
\text { normal controls }\end{array}$} \\
\hline & & & $\mathrm{VIP}^{\mathrm{b}}$ & P-value & $\mathrm{FC}^{\mathrm{d}}$ & $\mathrm{VIP}^{\mathrm{b}}$ & P-value & $\mathrm{FC}^{\mathrm{d}}$ \\
\hline Lysine & 3.77 & $\mathrm{~m}$ & 0.73 & $<0.001$ & 1.11 & 1.09 & $<0.001$ & 1.08 \\
\hline Glycolate & 3.93 & $\mathrm{~s}$ & 1.54 & $<0.001$ & -1.93 & 2.34 & $<0.001$ & -1.83 \\
\hline Serine & 3.98 & $\mathrm{~m}$ & 1.68 & $<0.001$ & 1.41 & 1.87 & $<0.001$ & 1.24 \\
\hline \multirow[t]{2}{*}{ Uracil } & 5.8 & $\mathrm{~d}$ & 1.58 & $<0.001$ & 4.17 & 2.15 & $<0.001$ & 3.67 \\
\hline & 7.54 & $\mathrm{~d}$ & 2.18 & $<0.001$ & 2.25 & 2.23 & $<0.001$ & 2.16 \\
\hline Tryptophan & 7.29 & $\mathrm{~m}$ & 1.55 & $<0.05$ & -1.18 & 0.96 & 0.061 & -1.11 \\
\hline Adenine & 8.12 & $\mathrm{~m}$ & 0.89 & $<0.001$ & 1.67 & 1.14 & $<0.001$ & 1.48 \\
\hline Formate & 8.45 & $\mathrm{~s}$ & 0.64 & $<0.05$ & 1.30 & 1.68 & $<0.001$ & 1.38 \\
\hline
\end{tabular}

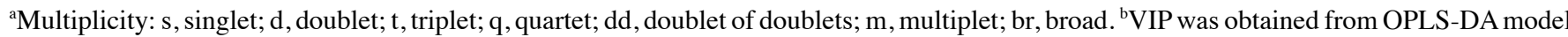
with a threshold of $1.0 .{ }^{\mathrm{C}} \mathrm{P}$-value was obtained using the Student's t-test. ${ }^{\mathrm{d}} \mathrm{FC}$ was calculated as a binary logarithm of the average mass response (normalized peak area) ratio between non-metastatic CRC samples vs. normal controls or between the metastatic CRC samples vs. normal controls, where a positive value indicated that the average mass response of the metabolite in the non-metastatic or metastatic group was higher than that in the normal controls, while a negative value indicated a relatively lower average mass as compared to normal controls. CRC, colorectal cancer; VIP, variable importance in the projection; FC, fold change; TMA, trimethylamine; DMG, dimethylglycine; PC, phosphocholine; GPC, glycerophosphocholine; OPLS-DA, orthogonal partial least squares-discriminant analysis.
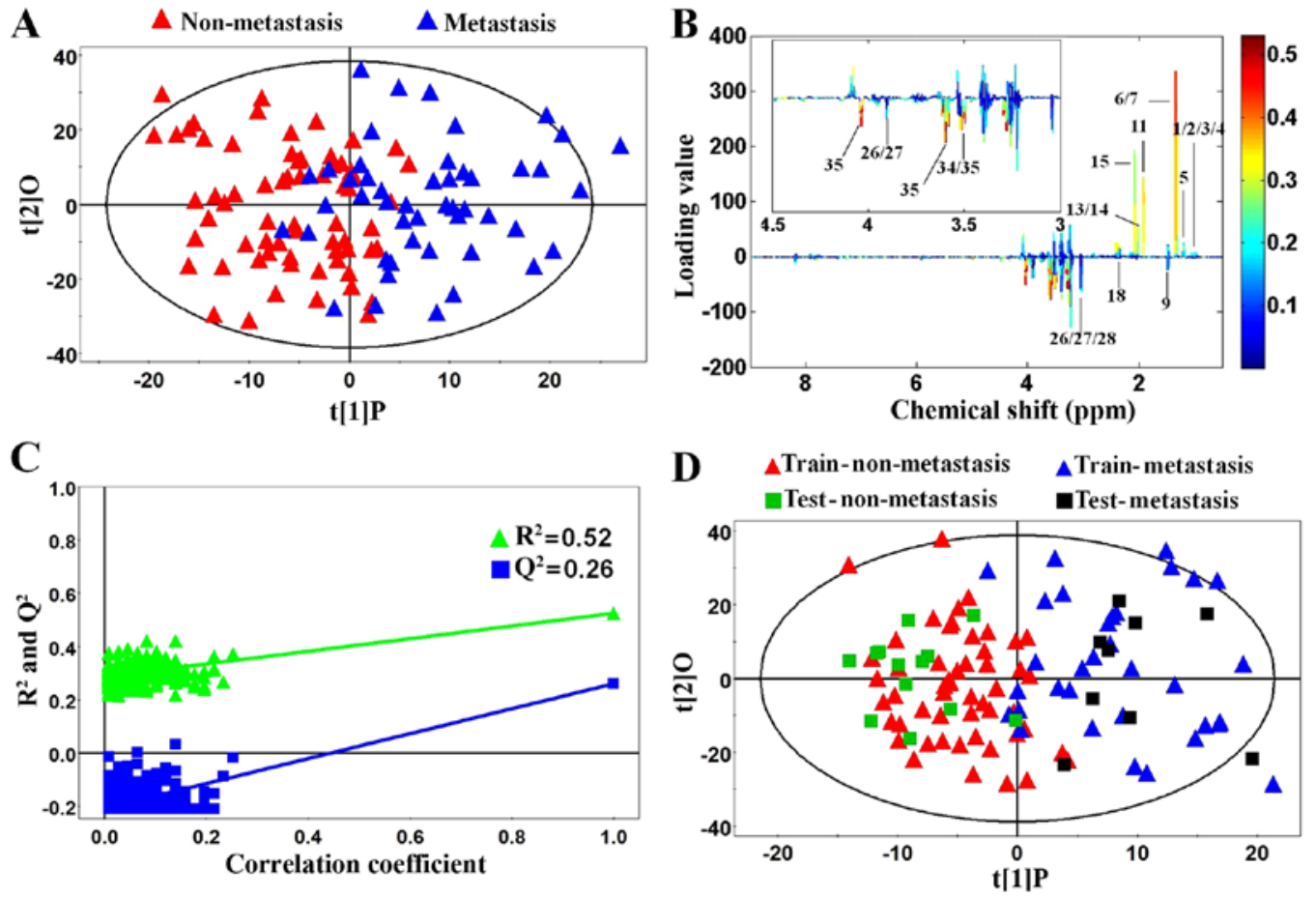

Figure 5. Discriminating plots of non-metastatic and metastatic CRC samples. (A) Score plot of the OPLS-DA model. Red triangles, non-metastatic CRC samples ( $n=73)$; blue triangles, metastatic CRC samples $(n=52)$. (B) The colormap shows the significance of metabolite variations between the two classes. Peaks in the positive direction indicate increased metabolites in the metastatic CRC samples in comparison to non-metastatic CRC samples. Deceased metabolites in the metastatic CRC samples are presented as peaks in the negative direction. (C) Statistical validation of the corresponding PLS-DA model using permutation analysis (200 times). $\mathrm{R}^{2}$ is the explained variance, and $\mathrm{Q}^{2}$ is the predictive ability of the model. (D) Score plot of OPLS-DA prediction model. A total of $80 \%$ of samples was applied to construct the model, and it was then used to predict the remaining $20 \%$ of the samples. CRC, colorectal cancer; OPLS-DA, orthogonal partial least squares-discriminant analysis; PLS-DA, partial least squares-discriminant analysis.

in Fig. 5D, the major testing samples were predicted correctly, which proved that lymph node metastasis could be used to stage CRC patients into two subgroups with different prognostic effects.
Tissue metabolic biomarker selection and altered metabolic pathways. We have listed 42 distinguishing tissue metabolites in Table II. Likewise, to further analyze the metabolic differences between the non-metastatic and metastatic CRC cases 
Table III. Differential metabolites identified between non-metastatic and metastatic CRC cases.

\begin{tabular}{|c|c|c|c|c|c|}
\hline \multirow[b]{2}{*}{ Metabolites } & \multirow[b]{2}{*}{ Chemical shift } & \multirow[b]{2}{*}{ Multiplicity ${ }^{\mathrm{a}}$} & \multicolumn{3}{|c|}{ Metastatic vs. non-metastatic } \\
\hline & & & VIP & P-value ${ }^{c}$ & $\mathrm{FC}^{\mathrm{d}}$ \\
\hline Thymine & 1.86 & $\mathrm{~d}$ & 1.07 & $<0.05$ & 1.24 \\
\hline Acetate & 1.93 & $\mathrm{~s}$ & 2.87 & $<0.001$ & 3.98 \\
\hline Lipid, $-\mathrm{C}_{2}-\mathrm{CH}_{2}-\mathrm{CH}=\mathrm{CH}-$ & 1.96 & br & 1.55 & $<0.05$ & 1.28 \\
\hline Acetic acid & 2.08 & $\mathrm{~s}$ & 2.24 & $<0.001$ & 4.09 \\
\hline Lipid, $-\mathrm{CH}_{2}-\mathrm{C}=\mathrm{O}$ & 2.26 & br & 1.18 & $<0.05$ & 1.09 \\
\hline Acetoacetic acid & 2.31 & $\mathrm{~s}$ & 1.10 & $<0.05$ & 1.16 \\
\hline Succinate & 2.41 & $\mathrm{~s}$ & 2.53 & $<0.001$ & 1.20 \\
\hline Dimethylglycine (DMG) & 2.73 & $\mathrm{~s}$ & 2.13 & $<0.001$ & 1.22 \\
\hline Sarcosine & 2.75 & $\mathrm{~s}$ & 1.17 & $<0.05$ & 1.17 \\
\hline Taurine & 3.27 & $\mathrm{t}$ & 3.75 & $<0.001$ & -1.19 \\
\hline & 3.43 & $\mathrm{t}$ & 0.70 & $<0.001$ & -1.30 \\
\hline
\end{tabular}

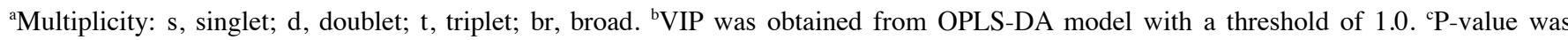
obtained using the Student's t-test. ${ }^{\mathrm{d}} \mathrm{FC}$ was calculated as a binary logarithm of the average mass response (normalized peak area) ratio between non-metastatic and metastatic CRC samples, where a positive value meant that the average mass response of the metabolite in the metastatic group was higher than that in the non-metastatic groups, while a negative value signified a relatively lower average mass as compared to the non-metastatic groups. CRC, colorectal cancer; VIP, variable importance in the projection; FC, fold change; OPLS-DA, orthogonal partial least squares-discriminant analysis.
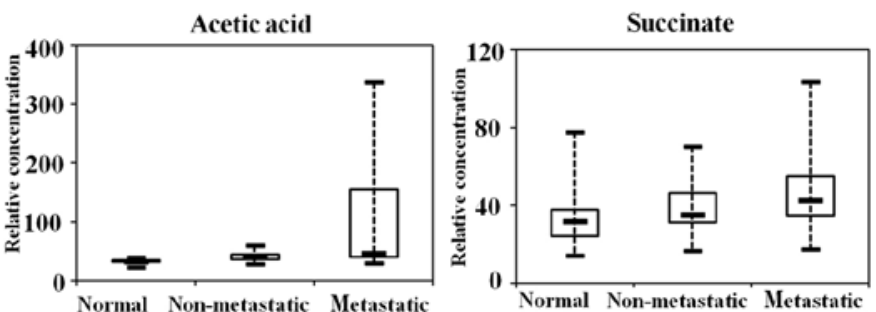

Thymine
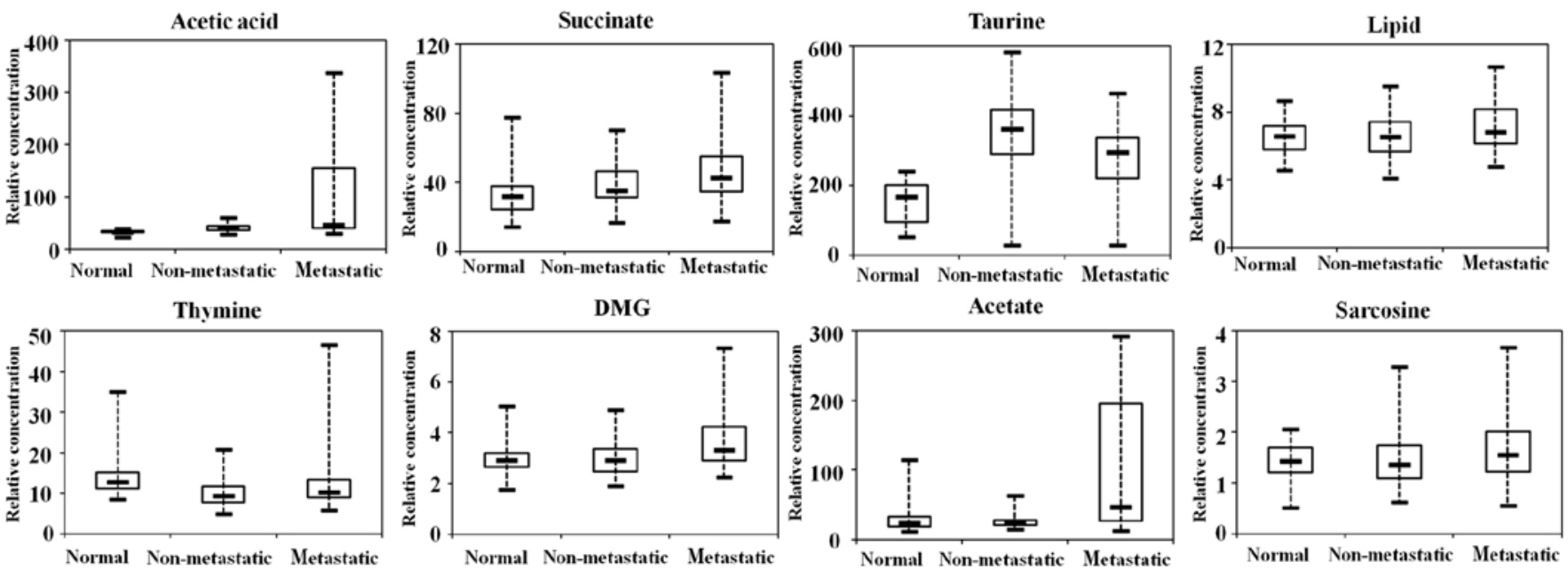

Figure 6. Box-and-whisker plots illustrating discrimination among normal controls, non-metastatic and metastatic CRC cases. Horizontal line in the middle portion of the box, median; bottom and top boundaries of boxes, 25th and 75th percentiles, respectively; lower and upper whiskers, the minimum and maximum value, respectively. CRC, colorectal cancer. DMG, dimethylglycine.

and identify the biomarkers in the process of lymph node metastasis, 10 tissue metabolites (VIP $>1$ and $\mathrm{p}<0.05$ ) were identified as potential biomarkers for use in discriminating between non-metastatic and metastatic CRC cases (Table III). In order to better show this result, the representative metabolites are displayed in box-and-whisker plots (Fig. 6), which show the concentration ranges, median quartiles and extremes. Acetate, a short-chain fatty acid secreted by propionibacteria from the human intestine, was significantly upregulated in metastatic patients in comparison with normal controls and non-metastatic cases. DMG, the product of the enzymatic conversion from betaine and as alternative methyl group donors during folate deficiency, was also increased in the metastatic CRC cases. The levels of succinate and taurine were elevated in the $\mathrm{CRC}$ cases rather than normal controls. However, thymine was decreased in the CRC samples.

To further understand the possible connections among these tissue metabolites, we proposed the related metabolic pathways based on the modified metabolites and the information obtained from the Kyoto Encyclopedia of Genes and Genomes website (www.genome.jp/kegg/), which is presented in Fig. 7. The changed metabolic pathways included glycolysis (glucose and lactate), fatty acid metabolism (lipids and myo-inositol), tricarboxylic acid (TCA) (succinate), urea 


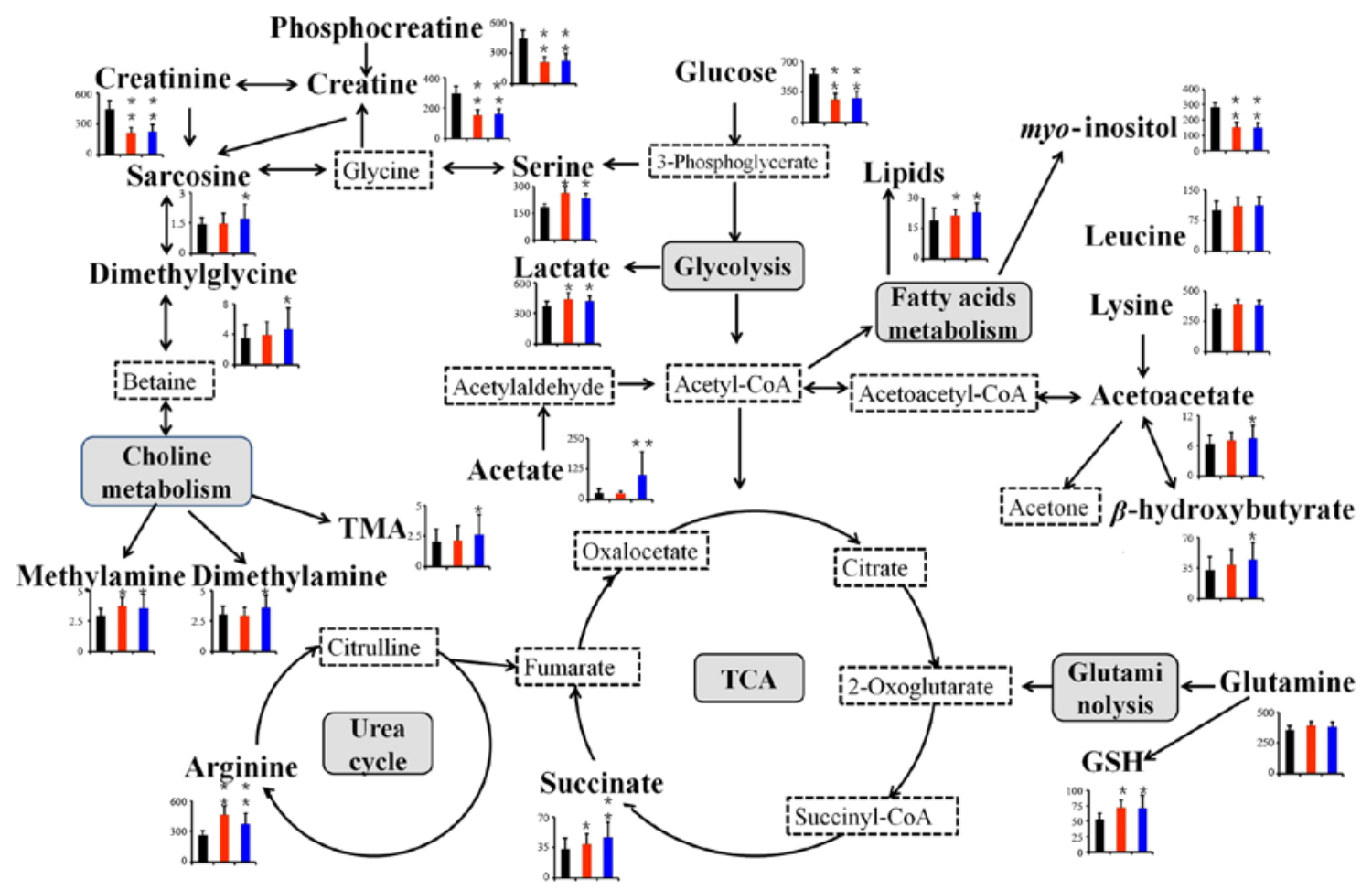

Figure 7. Metabolic pathways based on significantly altered metabolites between the CRC and normal control samples. Bar chart left to right: normal controls (blue bar), non-metastatic CRC samples (red bar), metastatic CRC samples (blue bar). The y-axis represents relative abundance of NMR signals (normalized to the total peaks). Dashed lines surrounding the compounds mean not measured or not significant between two groups. " $\mathrm{P}<0.05 ;{ }^{* * *} \mathrm{p}<0.01$. CRC, colorectal cancer; NMR, nuclear magnetic resonance; TCA, tricarboxylic acid; GSH, glutathione.

cycle (arginine), glutaminolysis (glutamine and glutamate), serine synthesis (serine and glycine), ketoplasia (acetoacetate, and $\beta$-hydroxybutyrate), choline metabolism [trimethylamine (TMA), dimethylamine (DMA), methylamine, dimethylglycine (DMG) and sarcosine] and amino acid metabolism (leucine, lysine, serine and glycine).

\section{Discussion}

In this research, we studied the metabolic profiling of human CRC tissues based on ${ }^{1} \mathrm{H}$ NMR, and analyzed the metabolic differences between the lymph node non-metastatic and metastatic CRC cases to identify the potential biomarkers involved in the progression of lymph node metastasis. In total, 42 distinguishing metabolites were identified, 28 of which were identified both in the non-metastatic and metastatic CRC samples. Among them, 10 metabolites were significantly altered between the non-metastatic and metastatic CRC samples, which could be used as potential biomarkers in discriminating the two classes. These modified metabolites included thymine, acetate, succinate, dimethylamine and sarcosine. Lymph node metastasis is the most important prognostic factor for CRC. Compared with previous studies concerning the metabolic profiling of human CRC samples $(13,16,19,27)$, to the best of our knowledge, the present study is the first to show the differences in the metabolic profile between non-metastatic and metastatic CRC cases. More importantly, we identified the specific altered metabolites between the two classes, which will be valuable in aiding accurate diagnosis and enhancing the understanding of the potential molecular mechanisms.
As shown in Fig. 7, many metabolic pathways are altered between CRC patients and normal controls. Compared with normal cells, cancer cells are characterized by increased glycolysis and glutaminolysis to meet the energy requirement for maintaining their rapid growth and proliferation $(28,29)$. The mean glucose levels were apparently lowered in the non-metastatic and metastatic CRC tissues, whereas lactate was consistently elevated, which matched previous reports $(30,31)$. Even in the presence of an adequate oxygen supply, most cancer cells prefer to produce two molecules of ATP through glycolytic breakdown of one molecule glucose instead of 36 molecules of ATP via mitochondrial oxidative phosphorylation, which is known as the Warburg effect (6). This process is less efficient, thus cancer cells must enhance glucose uptake. Along with the decrease in glucose, lactate was found to accumulate in CRC tissues. Lactate, as the end-product of glycolysis, is able to make the tumor microenvironment consistently acidic, which stimulates tumor cell metastasis in vivo and invasion in vitro $(26,32)$. In our study, the level of lactate was not significantly disturbed between non-metastatic and metastatic CRC tissues. Thus, glycolysis could play an important role in CRC development, while the acidic microenvironment may not be the main cause of lymph node metastasis in CRC.

In mammalian cells, glucose and glutamine are two of the most abundant nutrients to support energy, precursors for macromolecular synthesis, and substrates for other essential functions (33). Glutamine, as the most abundant amino acid, plays an important role in the metabolism of tumor cells and proliferating cells. Due to the Warburg effect, the amount of glucose-derived acetyl-CoA entering into the TCA cycle 
decreases significantly, as a result, glutaminolysis is an alternative source to replenish TCA cycle intermediates. Therefore, glutaminolysis plays a unique role in generating ATP and maintaining mitochondrial function. Increased glutaminolysis is an important metabolic characteristic of cancer cells (29). Glutamine also serves as a major source of nitrogen for biosynthesis, and a carbon substrate for anabolic processes in cancer cells (34). Glutamine can be converted to glutamate by glutaminase (GLS), releasing the amide nitrogen of glutamine as ammonia, which contributes to multiple biosynthetic pathways, including synthesis of other non-essential amino acids and nucleotides (35). Glutamate is converted to $\alpha$-ketoglutarate (AKG) by two types of reactions, which enters into TCA to support energy in the mitochondrion. Our results showed that glutamine was upregulated in CRC tissues, which suggested an excessive glutamine requirement to support the proliferation of CRC cells as alternative energy, carbon and nitrogen sources. Therefore the alternative modes of metabolism of glucose and glutamine enable cancer cells to resist metabolic stress and contribute to cancer cell survival and growth.

As an alternative process for glycolysis, the serine synthesis pathway (SSP) was activated in CRC tissues, the mechanism of which is poorly understood. Maddocks et al reported that cancer cells rapidly use exogenous serine under metabolic stress and serine deprivation-triggered activation of SSP, which suppresses glycolysis and increases flux to the TCA cycle (36). Therefore the utility of serine depletion will open a new therapeutic window in cancer cells that show some sensitivity to serine depletion. Moreover, serine is generated from the glycolytic intermediate 3-phosphoglycerate by 3-phosphoglycerate dehydrogenase (PHGDH). As a key metabolic enzyme of SSP, PHGDH was reported to be amplified in melanoma (37), esophageal adenocarcinoma and triple-negative breast cancer (38). Reducing PHGDH expression was found to impair cancer cell proliferation, whereas overexpression of PHGDH in human breast cells contributed to carcinogenesis by facilitating glycolysis to SSP (39). Our findings together with previous observations strongly support the hypothesis that disturbance of SSP occurred in human CRC.

Sarcosine ( $N$-methylglycine) is generated during the metabolism and catabolism of glycine. As a non-proteinogenic amino acid, it has a relationship with tumor progression and the metastatic process in prostate cancer and was studied as a sensitive tumor biomarker $(40,41)$. Moreover, sarcosine metabolism in metastatic breast cancer has yet to been investigated $(42,43)$. In our study, sarcosine was increased in metastatic CRC samples compared with that in non-metastatic CRC samples $(\mathrm{p}<0.05)$. Therefore, sarcosine may be a diagnostic marker in lymph node metastatic CRC; the underlying molecular mechanism needs further investigation.

Choline is an essential nutrient that is necessary in phospholipid metabolism of cell membranes and functions as an important methyl donor. It has been previously identified to play a significant role in malignant transformation of tissues (44). Choline is degraded through two pathways. One pathway involves the production of methylamines (methylamine, dimethylamine, TMA). The levels of methylamines were obviously upregulated in the CRC tissues in this study. The methylamines are usually regarded as non-toxic. However,
Lin et al reported that they may induce hepatocarcinogenesis in rats (45), thus we suspected that a similar phenomenon may exist in human. The abundant accumulation of the methylamines may indicate the disturbance of liver homeostasis in the development of $\mathrm{CRC}$, which is regarded as the primary target organ of CRC metastasis. The other pathway involves oxidation to betaine and donates a methyl group for homocysteine, finally forming methionine and DMG. Methionine is in turn converted into the universal methyl donor $S$-adenosyl methionine (SAM), as the methyl group required for phospholipid metabolism. In our study, DMG was significantly increased in metastatic CRC patients $(\mathrm{p}<0.001)$, which indicated that the second metabolic pathway of choline was activated. SAM is required for DNA methylation. Altered DNA methylation is important in CRC $(46,47)$. Moreover, the recent study reported that aberrant methylation was tightly related to lymph node metastasis of primary CRC (48). Therefore the disturbance in DMG may suggest some changes in epigenetic mechanisms of CRC, which induces lymph node metastasis. The upregulation of DMG may be a biomarker in the diagnosis and therapy of $\mathrm{CRC}$ in the future.

As a short-chain fatty acid, acetate is secreted by the intestinal diet propionibacteria, which induces mitochondrial apoptosis in CRC cells and may be relevant in CRC prevention and therapy $(49,50)$. In tumor cells, acetate is activated to form acetyl-CoA, which is a crucial central metabolite for fatty acid synthesis, TCA cycle, ketoplasia and various acetylation modifications of tumor cells. In our results, acetate was significantly increased in metastatic than non-metastatic CRC patients $(\mathrm{FC}=3.98)$. Lately, exogenous acetate was studied as an important alternative fuel for cancer cells (51). The exogenous acetate was reported to produce acetyl-CoA in the cytosol for epigenetic modifications and lipogenesis under metabolic stresses in primary or metastatic brain tumors (52). The incorporation of acetate is mediated by acetyl-CoA synthetase 2 (ACSS2). The increased ACSS2 was reported to play a critical role in diverse human tumor types $(51,52)$. Hypoxia-inducible factors (HIFs) are frequently activated in cancer and can promote cell survival in a tumor microenvironment of oxygen and glucose deficits. Acetate may stimulate tumor growth and metastasis in an ACSS2- and HIF-2-dependent manner (53). Moreover, Marques et al reported that acetate-induced apoptosis in CRC cells involved lysosomal membrane permeabilization and cathepsin D release (54). However, another study demonstrated that cathepsin D protected CRC cells from acetate-induced apoptosis through autophagy-independent degradation of damaged mitochondria (55). Thus, acetate has been proven to play a critical role in CRC development and metastasis, although the exact mechanism needs to be further investigated.

Cancer cells have increased reactive oxygen species (ROS) levels and a disturbed redox environment compared to normal cells, because of their accelerated metabolism, which distinguish them from normal cells $(56,57)$. The ROS in cancer is a double-edged sword. On the one hand, ROS plays a critical role in cancer cell development, proliferation, metastasis and survival by inducing DNA mutations, genomic instability and aberrant promoting tumorigenic cell signaling (58). However, on the other hand, the excessive ROS may also have a toxic 
effect on cancer cells and induce cell death signaling, senescence and cell cycle arrest (59). Therefore, various antioxidants exist to reduce ROS levels in cells. GSH is a main non-protein antioxidant in cancer cells, which is crucial for cell proliferation and apoptosis and can protect cancer cells from oxidative stress (60). Thus, in our study the increase in GSH in non-metastatic and metastatic CRC tissues compared to normal controls was the requirement of CRC to maintain their proliferation and survival. The metabolic pathway predominantly involved in GSH production is glutamine metabolism. Glutamine, as the precursor of glutamate, is required for GSH synthesis. The level of glutamine was also upregulated in our results, indicating a high demand of GSH to reduce the ROS in CRC. The contradictory 'doubled-edged sword' property of ROS makes antioxidants a target for cancer therapy. One study reported that the antioxidant treatment of overexpression of superoxide dismutase 3 (SOD3) inhibited breast cancer metastasis in a mouse xenograft model (61). Another study showed that $\mathrm{N}$-acetylcysteine (NAC) and vitamin E accelerated the progression of lung cancer by reducing ROS in mice (62). Chiang et al also exploited ROS and GSH dual redox-responsive polymer micelles for anticancer therapy (63). However, some long-term randomized controlled trials of antioxidant supplements did not prove that dietary antioxidant supplements were useful in primary cancer prevention $(64,65)$. Overall, the increased levels of glutamine and GSH during CRC progression suggest a progressive oxidative stress as well as a potential indicator for the development and metastasis of CRC, which may be a promising target of anticancer therapy.

Cancer is considered to be a type of metabolic disease with enhanced metabolism, since malignant cells require more amino acids to synthesize proteins and nucleic acids. The levels of some amino acids were reported to be higher in cancer than in normal controls $(25,66)$. Our results were also consistent with previous studies. In our study, the levels of leucine, isoleucine, valine, alanine, threonine, glutamine, arginine, lysine and serine were increased in the CRC tissues. As branched-chain amino acids (BCAA), leucine, isoleucine and valine are known to play a number of roles, such as in muscle protein synthesis, insulin secretion, and energy production through their catabolism (67). Threonine and methionine (produced by choline metabolism in our results) are both essential for maintaining the levels of SAM, which is important for subsequent epigenetic regulation in cancer cells. The increased serine indicated that the SSP was activated, which suppresses glycolysis and increases flux to TCA (35). Alanine and glutamine, as the key protein-derived glucose precursor, are subsequently used by hepatic gluconeogenesis, which produces a heavier burden for cancer patients. Arginine has long been recognized as a critical nutrient for tissue healing and an important component of immunonutrition. Dietary therapy containing arginine and other components is associated with the improvement of T-cell function (68). In addition, there is evidence suggesting that arginine stimulates tumor growth (68). However, the tryptophan was decreased in CRC tissues compared to normal controls. Previous studies showed that tryptophan was involved in a reduced immune response mediated by indoleamine 2,3-dioxygenase (IDO), which catalyzes tryptophan to produce kynurenine (69). So the downregulation of tryptophan in CRC tissues possibly suggested a strong tryptophan catabolism and an improved cancer cell immune escape in CRC. In a word, the disturbances of amino acid catabolism reflected the needs for the rapid proliferation and development of cancer cells.

In the present study, we globally analyzed the tissue profiling and identified the characteristic metabolites related to the carcinogenesis and metastasis of CRC based on ${ }^{1} \mathrm{H}$ NMR spectroscopy combined with multivariate statistical analysis. CRC patients were not only different from the healthy controls, but also well-classified according to lymph node metastasis by an OPLS-DA analysis. We identified a total of 10 tissue metabolite markers related to CRC lymph metastasis, of which acetate and acetic acid were important ( $\mathrm{FC}>3$ ). Certainly, the mechanism and clinical application will need future study. As far as we know, the present study is the first to analyze the metabolic prolifing between non-metastatic and metastatic CRC samples. The identified metabolites may be valuable in monitoring the neoplasia, invasion and metastasis of tumors. Further functional study and more clinical sample analysis are needed to demonstrate the potential application and the related mechanisms underlying CRC.

\section{Acknowledgements}

This study was supported by the Project of the National Natural Science Foundation of China (no. 81502096).

\section{References}

1. Weitz J, Koch M, Debus J, Höhler T, Galle PR and Büchler MW: Colorectal cancer. Lancet 365: 153-165, 2005.

2. Jemal A, Siegel R, Xu J and Ward E: Cancer statistics, 2010. CA Cancer J Clin 60: 277-300, 2010.

3. Siegel RL, Miller KD and Jemal A: Cancer statistics, 2015. CA Cancer J Clin 65: 5-29, 2015.

4. Siegel R, Ma J, Zou Z and Jemal A: Cancer statistics, 2014. CA Cancer J Clin 64: 9-29, 2014.

5. Abstracts from the 38th annual meeting of the society of general internal medicine. J Gen Intern Med 30 (Suppl 2): 45-551, 2015.

6. Warburg O: On the origin of cancer cells. Science 123: 309-314, 1956.

7. Muñoz-Pinedo C, El Mjiyad N and Ricci JE: Cancer metabolism: Current perspectives and future directions. Cell Death Dis 3: e248, 2012.

8. Jain M, Nilsson R, Sharma S, Madhusudhan N, Kitami T, Souza AL, Kafri R, Kirschner MW, Clish CB and Mootha VK: Metabolite profiling identifies a key role for glycine in rapid cancer cell proliferation. Science 336: 1040-1044, 2012.

9. Gross S, Cairns RA, Minden MD, Driggers EM, Bittinger MA, Jang HG, Sasaki M, Jin S, Schenkein DP, Su SM, et al: Cancer-associated metabolite 2-hydroxyglutarate accumulates in acute myelogenous leukemia with isocitrate dehydrogenase 1 and 2 mutations. J Exp Med 207: 339-344, 2010.

10. Fiehn O: Metabolomics - the link between genotypes and phenotypes. Plant Mol Biol 48: 155-171, 2002.

11. Song H, Wang L, Liu HL, Wu XB, Wang HS, Liu ZH, Li Y, Diao DC, Chen HL and Peng JS: Tissue metabolomic fingerprinting reveals metabolic disorders associated with human gastric cancer morbidity. Oncol Rep 26: 431-438, 2011.

12. Nicholson JK, Connelly J, Lindon JC and Holmes E: Metabonomics: A platform for studying drug toxicity and gene function. Nat Rev Drug Discov 1: 153-161, 2002.

13. Qiu Y, Cai G, Zhou B, Li D, Zhao A, Xie G, Li H, Cai S, Xie D, Huang C, et al: A distinct metabolic signature of human colorectal cancer with prognostic potential. Clin Cancer Res 20: 2136-2146, 2014.

14. Jung J, Jung Y, Bang EJ, Cho SI, Jang YJ, Kwak JM, Ryu H, Park S and Hwang GS: Noninvasive diagnosis and evaluation of curative surgery for gastric cancer by using NMR-based metabolomic profiling. Ann Surg Oncol 21 (Suppl 4): S736-S742, 2014. 
15. Li Y, Song X, Zhao X, Zou L and Xu G: Serum metabolic profiling study of lung cancer using ultra high performance liquid chromatography/quadrupole time-of-flight mass spectrometry. J Chromatogr B Analyt Technol Biomed Life Sci 966: 147-153, 2014.

16. Chen C, Deng L, Wei S, Nagana Gowda GA, Gu H, Chiorean EG, Abu Zaid M, Harrison ML, Pekny JF, Loehrer PJ, et al: Exploring metabolic profile differences between colorectal polyp patients and controls using seemingly unrelated regression. J Proteome Res 14: 2492-2499, 2015.

17. Ganti S, Taylor SL, Abu Aboud O, Yang J, Evans C, Osier MV, Alexander DC, Kim K and Weiss RH: Kidney tumor biomarkers revealed by simultaneous multiple matrix metabolomics analysis. Cancer Res 72: 3471-3479, 2012.

18. Griffin JL and Shockcor JP: Metabolic profiles of cancer cells. Nat Rev Cancer 4: 551-561, 2004.

19. Zhu J, Djukovic D, Deng L, Gu H, Himmati F, Chiorean EG and Raftery D: Colorectal cancer detection using targeted serum metabolic profiling. J Proteome Res 13: 4120-4130, 2014

20. Nuñez-Sánchez MA, García-Villalba R, Monedero-Saiz T, García-Talavera NV, Gómez-Sánchez MB, Sánchez-Álvarez C, García-Albert AM, Rodríguez-Gil FJ, Ruiz-Marín M, Pastor-Quirante FA, et al: Targeted metabolic profiling of pomegranate polyphenols and urolithins in plasma, urine and colon tissues from colorectal cancer patients. Mol Nutr Food Res 58: 1199-1211, 2014

21. Cheng Y, Xie G, Chen T, Qiu Y, Zou X, Zheng M, Tan B, Feng B, Dong T, He P, et al: Distinct urinary metabolic profile of human colorectal cancer. J Proteome Res 11: 1354-1363, 2012.

22. Beckonert O, Keun HC, Ebbels TM, Bundy J, Holmes E, Lindon JC and Nicholson JK: Metabolic profiling, metabolomic and metabonomic procedures for NMR spectroscopy of urine, plasma, serum and tissue extracts. Nat Protoc 2: 2692-2703, 2007.

23. Hu Z, Deng Y, Hu C, Deng P, Bu Q, Yan G, Zhou J, Shao X, Zhao J, Li Y, et al: ${ }^{1} \mathrm{H}$ NMR-based metabonomic analysis of brain in rats of morphine dependence and withdrawal intervention. Behav Brain Res 231: 11-19, 2012.

24. Wang H, Wang L, Zhang H, Deng P, Chen J, Zhou B, Hu J, Zou J, $\mathrm{Lu} \mathrm{W}$, Xiang P, et al: ${ }^{1} \mathrm{H}$ NMR-based metabolic profiling of human rectal cancer tissue. Mol Cancer 12: 121, 2013

25. Feng J, Liu H, Bhakoo KK, Lu L and Chen Z: A metabonomic analysis of organ specific response to USPIO administration. Biomaterials 32: 6558-6569, 2011.

26. Gu Y, Chen T, Fu S, Sun X, Wang L, Wang J, Lu Y, Ding S, Ruan G, Teng L, et al: Perioperative dynamics and significance of amino acid profiles in patients with cancer. J Transl Med 13: 35,2015 .

27. Martínez-Zaguilán R, Seftor EA, Seftor RE, Chu YW, Gillies RJ and Hendrix MJ: Acidic $\mathrm{pH}$ enhances the invasive behavior of human melanoma cells. Clin Exp Metastasis 14: 176-186, 1996.

28. Williams MD, Zhang X, Park JJ, Siems WF, Gang DR, Resar LM Reeves R and Hill HH Jr: Characterizing metabolic changes in human colorectal cancer. Anal Bioanal Chem 407: 4581-4595, 2015.

29. Vander Heiden MG, Cantley LC and Thompson CB: Understanding the Warburg effect: The metabolic requirements of cell proliferation. Science 324: 1029-1033, 2009.

30. Daye D and Wellen KE: Metabolic reprogramming in cancer: Unraveling the role of glutamine in tumorigenesis. Semin Cell Dev Biol 23: 362-369, 2012.

31. Holst S, Stavenhagen K, Balog CI, Koeleman CA, McDonnell LM, Mayboroda OA, Verhoeven A, Mesker WE, Tollenaar RA, Deelder AM, et al: Investigations on aberrant glycosylation of glycosphingolipids in colorectal cancer tissues using liquid chromatography and matrix-assisted laser desorption time-of-flight mass spectrometry (MALDI-TOF-MS). Mol Cell Proteomics 12 3081-3093, 2013

32. Ni Y, Xie G and Jia W: Metabonomics of human colorectal cancer: New approaches for early diagnosis and biomarker discovery. J Proteome Res 13: 3857-3870, 2014.

33. Schlappack OK, Zimmermann A and Hill RP: Glucose starvation and acidosis: Effect on experimental metastatic potential, DNA content and MTX resistance of murine tumour cells. Br J Cancer 64: 663-670, 1991.

34. Dang CV: Links between metabolism and cancer. Genes Dev 26 : 877-890, 2012

35. Pan T, Gao L, Wu G, Shen G, Xie S, Wen H, Yang J, Zhou Y, Tu Z and Qian W: Elevated expression of glutaminase confers glucose utilization via glutaminolysis in prostate cancer. Biochem Biophys Res Commun 456: 452-458, 2015.
36. Maddocks OD, Berkers CR, Mason SM, Zheng L, Blyth K, Gottlieb E and Vousden KH: Serine starvation induces stress and p53-dependent metabolic remodelling in cancer cells. Nature 493: 542-546, 2013.

37. Locasale JW, Grassian AR, Melman T,Lyssiotis CA, Mattaini KR, Bass AJ, Heffron G, Metallo CM, Muranen T, Sharfi H, et al: Phosphoglycerate dehydrogenase diverts glycolytic flux and contributes to oncogenesis. Nat Genet 43: 869-874, 2011.

38. Locasale JW and Cantley LC: Genetic selection for enhanced serine metabolism in cancer development. Cell Cycle 10: 3812-3813, 2011.

39. Possemato R, Marks KM, Shaul YD, Pacold ME, Kim D, Birsoy K, Sethumadhavan S, Woo HK, Jang HG, Jha AK, et al: Functional genomics reveal that the serine synthesis pathway is essential in breast cancer. Nature 476: 346-350, 2011.

40. Khan AP, Rajendiran TM, Ateeq B, Asangani IA, Athanikar JN, Yocum AK, Mehra R, Siddiqui J, Palapattu G, Wei JT, et al: The role of sarcosine metabolism in prostate cancer progression. Neoplasia 15: 491-501, 2013.

41. Baum CE, Price DK and Figg WD: Sarcosine as a potential prostate cancer biomarker and therapeutic target. Cancer Biol Ther 9: 341-342, 2010.

42. Cha YJ, Kim H, Jung WH and Koo JS: Expression of sarcosine metabolism-related proteins according to metastatic site in breast cancer. Int J Clin Exp Pathol 7: 7824-7833, 2014.

43. Cha YJ, Jung WH, Cho NH and Koo JS: Expression of sarcosine metabolism-related proteins in invasive lobular carcinoma: Comparison to invasive ductal carcinoma. Yonsei Med J 56: 598-607, 2015.

44. Glunde K, Bhujwalla ZM and Ronen SM: Choline metabolism in malignant transformation. Nat Rev Cancer 11: 835-848, 2011.

45. Lin JK and Ho YS: Hepatotoxicity and hepatocarcinogenicity in rats fed squid with or without exogenous nitrite. Food Chem Toxicol 30: 695-702, 1992.

46. Lin PC, Lin JK, Lin CH, Lin HH, Yang SH, Jiang JK, Chen WS, Chou CC, Tsai SF and Chang SC: Clinical relevance of plasma DNA methylation in colorectal cancer patients identified by using a genome-wide high-resolution array. Ann Surg Oncol 22 (Suppl 3): S1419-S1427, 2015.

47. Michailidi C, Theocharis S, Tsourouflis G, Pletsa V, Kouraklis G, Patsouris E, Papavassiliou AG and Troungos C: Expression and promoter methylation status of hMLH1, MGMT, APC, and CDH1 genes in patients with colon adenocarcinoma. Exp Biol Med (Maywood) 240: 1599-1605, 2015.

48. Nakamura K, Yamashita K, Sawaki H, Waraya M, Katoh H, Nakayama N, Kawamata H, Nishimiya H, Ema A, Narimatsu H, et al: Aberrant methylation of GCNT2 is tightly related to lymph node metastasis of primary CRC. Anticancer Res 35: 1411-1421, 2015.

49. Hinnebusch BF, Meng S, Wu JT, Archer SY and Hodin RA: The effects of short-chain fatty acids on human colon cancer cell phenotype are associated with histone hyperacetylation. J Nutr 132: 1012-1017, 2002.

50. Lan A, Lagadic-Gossmann D, Lemaire C, Brenner C and Jan G: Acidic extracellular pH shifts colorectal cancer cell death from apoptosis to necrosis upon exposure to propionate and acetate, major end-products of the human probiotic propionibacteria. Apoptosis 12: 573-591, 2007.

51. Comerford SA, Huang Z, Du X, Wang Y, Cai L, Witkiewicz AK, Walters H, Tantawy MN, Fu A, Manning HC, et al: Acetate dependence of tumors. Cell 159: 1591-1602, 2014.

52. Mashimo T, Pichumani K, Vemireddy V, Hatanpaa KJ, Singh DK, Sirasanagandla S, Nannepaga S, Piccirillo SG, Kovacs Z, Foong C, et al: Acetate is a bioenergetic substrate for human glioblastoma and brain metastases. Cell 159: 1603-1614, 2014.

53. Chen R, Xu M, Nagati JS, Hogg RT, Das A, Gerard RD and Garcia JA: The acetate/ACSS2 switch regulates HIF-2 stress signaling in the tumor cell microenvironment. PLoS One 10: e0116515, 2015.

54. Marques C, Oliveira CS, Alves S, Chaves SR, Coutinho OP, Côrte-Real M and Preto A: Acetate-induced apoptosis in colorectal carcinoma cells involves lysosomal membrane permeabilization and cathepsin D release. Cell Death Dis 4: e507, 2013.

55. Oliveira CS, Pereira H, Alves S, Castro L, Baltazar F, Chaves SR, Preto A and Côrte-Real M: Cathepsin D protects colorectal cancer cells from acetate-induced apoptosis through autophagy-independent degradation of damaged mitochondria. Cell Death Dis 6: e1788, 2015. 
56. Nogueira V and Hay N: Molecular pathways: reactive oxygen species homeostasis in cancer cells and implications for cancer therapy. Clin Cancer Res 19: 4309-4314, 2013.

57. Glasauer A and Chandel NS: Targeting antioxidants for cancer therapy. Biochem Pharmacol 92: 90-101, 2014

58. Weinberg F, Hamanaka R, Wheaton WW, Weinberg S, Joseph J, Lopez M, Kalyanaraman B, Mutlu GM, Budinger GR and Chandel NS: Mitochondrial metabolism and ROS generation are essential for Kras-mediated tumorigenicity. Proc Natl Acad Sci USA 107: 8788-8793, 2010.

59. Moon DO, Kim MO, Choi YH, Hyun JW, Chang WY and Kim GY: Butein induces G(2)/M phase arrest and apoptosis in human hepatoma cancer cells through ROS generation. Cancer Lett 288: 204-213, 2010.

60. Fiser B, Szori M, Jójárt B, Izsák R, Csizmadia IG and Viskolcz B: Antioxidant potential of glutathione: A theoretical study. J Phys Chem B 115: 11269-11277, 2011.

61. Teoh-Fitzgerald ML, Fitzgerald MP, Zhong W, Askeland RW and Domann FE: Epigenetic reprogramming governs EcSOD expression during human mammary epithelial cell differentiation, tumorigenesis and metastasis. Oncogene 33: 358-368, 2014.

62. Silani V: Editorial on the original article entitled 'Genetic validation of a therapeutic target in a mouse model of ALS' published in the Science Translational Medicine on August 6, 2014. Ann Transl Med 3 (Suppl 1): S27, 2015.
63. Chiang YT, Yen YW and Lo CL: Reactive oxygen species and glutathione dual redox-responsive micelles for selective cytotoxicity of cancer. Biomaterials 61: 150-161, 2015.

64. Qiao YL, Dawsey SM, Kamangar F, Fan JH, Abnet CC, Sun XD, Johnson LL, Gail MH, Dong ZW, Yu B, et al: Total and cancer mortality after supplementation with vitamins and minerals: Follow-up of the Linxian General Population Nutrition Intervention Trial. J Natl Cancer Inst 101: 507-518, 2009.

65. Klein EA, Thompson IM Jr, Tangen CM, Crowley JJ, Lucia MS, Goodman PJ, Minasian LM, Ford LG, Parnes HL, Gaziano JM, et al: Vitamin E and the risk of prostate cancer: The Selenium and Vitamin E Cancer Prevention Trial (SELECT). JAMA 306: 1549-1556, 2011.

66. Brosnan JT and Brosnan ME: Branched-chain amino acids: Enzyme and substrate regulation. J Nutr 136 (Suppl): 207S-211S, 2006.

67. Zhu X, Herrera G and Ochoa JB: Immunosupression and infection after major surgery: A nutritional deficiency. Crit Care Clin 26: 491-500, 2010.

68. Phillips MM, Sheaff MT and Szlosarek PW: Targeting arginine-dependent cancers with arginine-degrading enzymes: Opportunities and challenges. Cancer Res Treat 45: 251-262, 2013.

69. Platten M, Wick W and Van den Eynde BJ: Tryptophan catabolism in cancer: Beyond IDO and tryptophan depletion. Cancer Res 72: 5435-5440, 2012. 